\section{Qualidade parasitológica e condições higiênico-sanitárias de hortaliças comercializadas na cidade de Florianópolis, Santa Catarina, Brasil}

\author{
Parasitological quality and \\ hygienic-sanitary conditions of \\ vegetables sold in the city of \\ Florianópolis, Santa Catarina, Brazil
}

\section{Bolivar Soares ${ }^{1}$}

\section{Geny Aparecida Cantos ${ }^{1}$}

'Departamento de Análises Clínicas, Universidade Federal de Santa Catarina (UFSC)

\section{Resumo}

Embora as hortaliças sejam amplamente comercializadas e consumidas no Brasil, o consumo de verduras cruas constitui importante meio de transmissão de parasitas intestinais. Neste estudo, avaliou-se a presença de formas transmissíveis de três tipos de hortaliças (rúcula, agrião e alfacecrespa) comercializadas em cinco principais pontos de venda aos consumidores (dois supermercados, dois "sacolões" e em uma feira livre), na cidade de Florianópolis, Santa Catarina, Brasil, no período de junho 2003 a maio 2004. As hortaliças in natura foram lavadas com água e esta foi submetida ao método de sedimentação, durante um período de 24 horas. Concomitante à pesquisa laboratorial, foram avaliadas as condições de cultivo e manipulação de diferentes produtores agrícolas, os quais forneciam as hortaliças que eram posteriormente comercializadas em Florianópolis. A análise parasitológica mostrou alta freqüência de parasitas intestinais na maioria das amostras analisadas (40\% a 76\%). Entre os fatores envolvidos na contaminação das verduras, destacaram-se a origem das águas de irrigação, o acondicionamento, o transporte e a manipulação destas durante a coleta. Conclui-se que as hortaliças comercializadas nesta região têm relevante papel na transmissão de enfermidades intestinais, havendo necessidade de medidas específicas que evitem a contaminação desses vegetais.

Palavras-chave: Hortaliças. Enteroparasitas. Qualidade parasitológica. 


\section{Abstract}

Although vegetables are widely sold and consumed in Brazil, the ingestion of raw vegetables is an important way of transmission of intestinal parasites. In this study, the presence of transmissible forms of intestinal parasites in three vegetable species commercially available in five very busy locations (two supermarkets, two "kilo markets" and a street market) located in the city of Florianópolis, Santa Catarina, Brazil, within the period between June 2003 and May 2004 was evaluated. The in natura vegetables were washed with water and the washing water was submitted to the spontaneous sedimentation method for a period of 24 hours. Concomitantly to the laboratory research, the conditions of cultivation and manipulation of the producers of the vegetables sold in Florianópolis were evaluated. The parasitologic analysis confirmed the presence of intestinal parasites in most of the vegetables analyzed $(40 \%$ to $76 \%$ ). Among the factors involved in the contamination of vegetables, the origin of the water used for irrigation, storage and transportation of vegetables and the degree of manipulation during the sampling process can be included. From the results, it can be concluded that vegetables sold in the investigated region play an important role in the transmission of intestinal diseases, and, therefore, specific measures should to be taken in order to avoid the contamination of these vegetables.

Keywords: Vegetables. Intestinal parasites. Parasitologic quality.

\section{Introdução}

As parasitoses intestinais, devido a sua elevada prevalência e diversidade de manifestações clínicas, representam um problema de grande importância em Saúde Pública, uma vez que aproximadamente um terço da população brasileira vive em condições ambientais propícias à disseminação das infecções parasitárias ${ }^{1,2}$.

O Brasil, como um país tropical em desenvolvimento, possui clima e situação socioeconômica favoráveis à ocorrência de doenças parasitárias. Tanto nas áreas rurais quanto nas urbanas, nos países em desenvolvimento, as parasitoses intestinais são amplamente difundidas devido às más condições sanitárias, e as hortaliças servem como um dos principais veículos de transmissão de enfermidades intestinais ${ }^{3,4}$.

As condições de higiene ambiental refletem as condições sanitárias em que vive o homem, e estas por sua vez, parecem exercer profunda influência na cadeia de transmissão das enteroparasitoses. O indivíduo parasitado, por meio de seus dejetos, contamina seu próprio ambiente com ovos, cistos e larvas de parasitas intestinais, e a água pode acumulá-los e transportá-los a grandes distâncias. Assim, as fezes representam o veículo e a fonte de contaminação de todos os parasitas intestinai ${ }^{5-7}$. Na transmissão dos parasitas intestinais, destacam-se o solo, o ar, a água, as moscas, as mãos e os alimentos (incluindo as verduras) como os principais elementos que compõem o ciclo da cadeia epidemiológica das helmintoses e protozooses ${ }^{8}$.

A manipulação de alimentos em condições precárias de higiene também é um fator importante na transmissão de enteroparasitas $^{9,10}$. Indivíduos que manipulam alimentos podem também representar fonte potencial de contaminação e disseminação de enteroparasitas, embora estejam, na maioria das vezes, na condição de assintomáticos ${ }^{11}$. 
As hortaliças, em especial as consumidas em saladas, podem conter larvas e ovos de helmintos e cistos de protozoários, provenientes de águas contaminadas por dejetos fecais de animais e/ou de homem ${ }^{4}$. Um estudo-piloto realizado em Florianópolis mostrou que todas as amostras analisadas de alface e agrião provenientes de um "sacolão" continham um ou mais tipos de enteroparasitas, sendo a Giardia lamblia o parasita mais prevalente, seguido de Entamoeba coli e Endolimax nana ${ }^{12}$.

Dando continuidade a este estudo, este trabalho considerou a possibilidade de monitorar a contaminação fecal ambiental por meio da pesquisa de enteroparasitas em hortaliças comercializadas em diferentes pontos de comercialização de uma cidade brasileira, fornecendo dados para a Saúde Pública e a Vigilância Sanitária sobre as condições higiênico-sanitárias desses produtos. Posteriormente, espera-se explicitar a horticultores e a manipuladores de alimentos um sistema preventivo e dinâmico, de forma que se possa influir de maneira significativa na qualidade das hortaliças consumidas pela população.

\section{Materiais e Métodos}

Foram colhidas e analisadas, em triplicata, 750 amostras das seguintes hortaliças de cultivo tradicional: alface (Lactuva sativa) variedade crespa, rúcula (Chicarium $s p$ ) e agrião (Nasturtium officinale). Estabeleceu-se, como unidade amostral para as alfaces, o pé (ou touceira), independentemente do peso ou tamanho que apresentassem, enquanto para o agrião e a rúcula considerou-se o maço, constituído de folhas agrupadas e amarradas por um laço.

A coleta foi realizada no período da manhã, em cinco principais pontos de comercialização de hortaliças em Florianópolis, localizados no Estado de Santa Catarina. Foram colhidas, aleatoriamente, amostras que estavam à disposição do consumidor, sendo obtidas de dois "sacolões", dois supermercados, e de uma feira livre, entre os meses de junho de 2003 a maio de 2004. Em cada ponto de comercialização foram colhidas aproximadamente 15 amostras por semana até completar 150.

Todas as hortaliças comercializadas nestes estabelecimentos foram cultivadas no município de Antônio Carlos, pertencente à Grande Florianópolis, que possui uma área superficial de $205 \mathrm{~km}^{2}$, cuja economia é baseada na agropecuária. Para investigação das condições de cultivo e manipulação das hortaliças, utilizou-se uma entrevista padronizada, elaborada a partir de um questionário semi-estruturado, contendo perguntas sobre o sistema de água de irrigação, o tipo de adubo utilizado, processamento de alguma técnica de lavagem na pós-colheita, o uso de luvas por manipuladores, o transporte das hortaliças; se as hortaliças eram embaladas no local de produção para o local de comercialização, a presença de sistema pecuarista e alvará da prefeitura.

Para a elaboração de um diagnóstico preliminar, nove diferentes produtores rurais participaram desta pesquisa, cujos objetivos foram explicados aos participantes, tendo sido obtido destes o termo de livre consentimento para que a pesquisa pudesse ser publicada.

As hortaliças comercializadas na feira livre eram produzidas em uma pequena propriedade, sendo o entrevistado o responsável pela produção. Os fornecedores das hortaliças obtidas dos dois supermercados eram diferentes, e possuíam duas marcas de hortaliças com nomes distintos. Nesse caso foram entrevistados respectivamente os dois indivíduos responsáveis por estas propriedades. Em relação aos "sacolões", participaram desta pesquisa cinco produtores agrícolas que forneciam as hortaliças a esses estabelecimentos.

As amostras de hortaliças provenientes dos referidos pontos de comercialização foram acondicionadas, individualmente, em sacos plásticos limpos e descartáveis, 
sendo transportadas para análise ao Laboratório de Análises Clínicas da Universidade Federal de Santa Catarina.

No laboratório, utilizando-se luvas de borracha, as amostras foram fatiadas e homogeneizadas, separadamente, desprezando-se talos e raízes. Em seguida, $100 \mathrm{~g}$ de cada hortaliça foram pesadas e mergulhadas em $200 \mathrm{ml}$ de uma solução detergente $(0,3 \mathrm{mg} / \mathrm{ml}$ de lauril éter sulfato de sódio e $0,25 \mathrm{mg} / \mathrm{ml}$ de álcool láurico etoxilado), durante vinte minutos. Com a ajuda de um pincel, a superfície das folhas foi esfregada, permanecendo alguns segundos em repouso. Logo após, as folhas foram erguidas para escorrer completamente o líquido, e em seguida desprezadas. O líquido obtido foi filtrado posteriormente, por meio de um funil analítico com gaze, e recolhido em um frasco cônico. O recipiente que continha as verduras foi lavado duas vezes com $25 \mathrm{ml} \mathrm{de}$ solução detergente, recolhendo-se o líquido no mesmo frasco.

O filtrado ficou em repouso por 24 horas. Completada a sedimentação retiraram-se $5,0 \mathrm{ml}$ do sedimento que foi centrifugado a 1.500 rotações por minuto (rpm), durante dois minutos, desprezando-se o sobrenadante e ajustando-se o volume final do sedimento para $0,5 \mathrm{ml}$ com água destilada, sendo assim homogeneizado. Com o auxílio de uma micropipeta graduada, pipetou-se $0,05 \mathrm{ml}$ do sedimento, que foi examinado por meio de lâmina corada com solução de lugol, em exame direto com microscópio óptico. Foram utilizadas as objetivas de 10x e 40x, a fim de serem efetuadas, respectivamente, a identificação, e a confirmação e quantificação das estruturas parasitárias. A leitura foi realizada em triplicata, e o cálculo do número total de cistos, ovos e larvas nas amostras foi realizado conforme descrito por Oliveira e Germano ${ }^{13}$.

Para a análise das médias totais de cistos de protozoários e ovos e larvas de helmintos foi aplicado o teste de Tukey. Foram considerados estatisticamente significativos valores $<0,05^{14,15}$.

\section{Resultados}

A Tabela 1 mostra que as 750 hortaliças comercializadas e analisadas em Florianópolis apresentaram alto percentual de enteroparasitas (40,0\% a 73,3\%), e as hortaliças provenientes dos "sacolões" apresentaram maior número de cistos de protozoários, ovos e larvas de

Tabela 1 - Resultados obtidos das análises parasitológicas de três variedades de hortaliças (alface, rúcula e agrião) da cidade de Florianópolis SC, durante o período de junho de 2003 a maio de 2004.

Table 1 - Results from parasitologic analyses of three varieties of vegetables (lettuce, arugula and water cress) in the city of Florianópolis SC, during the June 2003 to May 2004 period.

\begin{tabular}{lccc}
\hline $\begin{array}{l}\text { Pontos de } \\
\text { comercialização }\end{array}$ & $\begin{array}{c}\text { Número de } \\
\text { amostras analisadas }\end{array}$ & $\begin{array}{c}\text { Contaminadas } \\
\mathrm{n} \%\end{array}$ & N.T. N.M. \\
\hline "Sacolão"1 & 150 & 11073,3 & $4660^{\mathrm{a}} 97,7$ \\
"Sacolão" 2 & 150 & 11476,0 & $9960^{\mathrm{ab}} 66,4$ \\
Supermercado 1 & 150 & 9261,3 & $9890^{\mathrm{ab}} 65,9$ \\
Supermercado 2 & 150 & 9160,6 & $6280^{\mathrm{bc}} 41,8$ \\
Feira livre & 150 & 6040,0 & $1860^{\mathrm{c}} 12,4$ \\
\hline
\end{tabular}

$\mathrm{n}=$ número de unidades contaminadas $/ \mathrm{n}=$ number of contaminated units.

$\%=$ percentagem de hortaliças parasitadas/ \%= percentage of vegetables with parasites.

N.T.= número total de ovos, cistos e larvas por $100 \mathrm{~g}$ de amostra.

N.T.= total number of eggs, cysts and larvae per $100 \mathrm{~g}$ of sample.

N.M. $=$ número ${ }^{\circ}$ médio de ovos, cistos e larvas por $100 \mathrm{~g}$ de amostra *"Tukey $=(p>0,05)$.

$N . M .=$ mean number ${ }^{0}$ of eggs, cysts and larvae per $100 \mathrm{~g}$ of sample ${ }^{* *} T u k e y=(p>0.05)$. 
helmintos do que as obtidas dos supermercados 1 e 2 e feira livre. Os valores médios dessas estruturas variaram de 97,7/100g de amostras para o "sacolão" 1, a 12,4/100g de amostra, para a feira livre. A aplicação do teste de Tukey para análise das médias totais mostra que colunas seguidas de letras iguais não diferiram entre si de forma significativa.

A Tabela 2 mostra os resultados das condições de cultivo e manipulação das hortaliças, considerando os diferentes fornecedores. Muitos agricultores que forneciam hortaliças para os "sacolões" utilizavam o esterco de boi para adubar a terra e água de rio, provavelmente contaminada, para irrigar a plantação de hortaliças, e não realizavam a lavagem pós-coleta. O uso de luvas durante a coleta foi um atributo apenas para os agricultores que forneciam hortaliças aos supermercados e feira livre, enquanto a embalagem dos referidos produtos era realizada somente pelos produtores que forneciam as verduras aos supermerca- dos. Outra questão levantada foi a forma como as hortaliças eram transportadas. Os produtores dos supermercados e um produtor dos "sacolões" utilizavam como meio de transporte um caminhão fechado e os demais, caminhão aberto. Foi observado também que somente os produtores que forneciam hortaliças para os dois supermercados apresentaram o alvará da prefeitura.

\section{Discussão}

É consenso que o consumo de frutas e verduras proporciona importantes benefícios à saúde, com implicações diretas na qualidade de vida. Nesse sentido, há um estímulo para que esses alimentos sejam consumidos, sobretudo na forma in natura. Contudo, são muitos os fatores que concorrem para a ocorrência de doenças parasitárias por meio da ingestão desses alimentos cultivados em áreas contaminadas com dejetos fecais ou irrigadas com águas poluídas ${ }^{16,17}$.

Tabela 2 - Dados levantados sobre as condições de cultivo e manipulação de hortaliças comercializadas em Florianópolis SC-Brasil, considerando os diferentes fornecedores

Table 2 - Data obtained from culture and handling conditions of vegetables sold in Florianópolis SC-Brasil, considering different suppliers

\begin{tabular}{|c|c|c|c|}
\hline \multirow{2}{*}{$\begin{array}{l}\text { Aspectos } \\
\text { epidemiológicos }\end{array}$} & \multicolumn{3}{|c|}{ Pontos de comercialização } \\
\hline & "Sacolões"1 e 2 & Supermercados 1 e 2 & Feira livre \\
\hline $\begin{array}{l}\text { Tipo de água } \\
\text { de irrigação }\end{array}$ & $\begin{array}{l}\text { rio }(1,2,4 \text { e } 5) \\
\text { córrego (3) }\end{array}$ & córrego & córrego \\
\hline Tipo de adubo & $\begin{array}{c}\text { esterco de boi (1) e } \\
\text { esterco de galinha ( } 2 \text { a } 5 \text { ) }\end{array}$ & $\begin{array}{l}\text { matéria orgânica decomposta* } \\
\text { e esterco de galinha** }\end{array}$ & esterco de galinha \\
\hline Lavagem pós-coleta & $\operatorname{sim}(1,4$ e 5$)$ e não (2 e 3$)$ & $\operatorname{sim}$ & $\operatorname{sim}$ \\
\hline Uso de luvas (coleta) & não (1 a 5 ) & $\operatorname{sim}$ & não \\
\hline Embalagem & sim (1e 5) e não (2, 3 e 4) & $\operatorname{sim}$ & não \\
\hline Transporte & $\begin{array}{l}\text { caminhão fechado (1)/ } \\
\text { caminhão aberto ( } 2 \text { a5) }\end{array}$ & caminhão fechado & caminhão aberto \\
\hline Sistema pecuarista & bovino (1, 3, 4 e 5), não (2) & não & bovino \\
\hline Alvará da prefeitura & não (1 a 5) & $\operatorname{sim}$ & não \\
\hline
\end{tabular}


O hábito alimentar de consumir hortaliças in natura possibilita a exposição de uma grande parcela da população às formas transmissíveis de parasitas ${ }^{12}$. O controle de doenças veiculadas por alimentos, que são resultantes do ciclo de contaminação fecaloral, tem recebido atenção maior em todo o mundo ${ }^{18,19}$. Em Florianópolis, apesar da rigorosa atuação da Vigilância Sanitária em estabelecimentos que trabalham com alimentos, recentemente foi verificado que indivíduos que atuavam em uma empresa de alimentos e trabalhadores de feiras livres e "sacolões" apresentavam um elevado grau de parasitismo, e os fatores socioeconômicos, como distribuição de renda, escolaridade e categorias ocupacionais, foram importantes dentro deste contexto ${ }^{10}$.

Diante deste fato, considerou-se que as hortaliças comercializadas em Florianópolis poderiam apresentar um papel importante na transmissão das enteroparasitoses. Uma forma de avaliar tal pressuposto foi realizar exames parasitológicos de hortaliças provenientes de diversos pontos de comercialização preferidos pela população local e turística. Esses estabelecimentos têm uma localização central e possuem uma grande variedade de frutas e verduras. As hortaliças examinadas neste trabalho foram as variedades mais comercializadas e mais consumidas cruas pela população brasileira.

No Brasil, a presença destacada de "sacolões" tem fornecido uma nova opção para população, sobretudo no que diz respeito ao preço mais acessível, pois esses produtos são comprados em conjunto e por quilo. Por outro lado, os supermercados têm assumido cada vez mais um papel central no cotidiano dos consumidores por comercializarem uma demanda mais ampla de alimentos e por manterem por mais tempo o estabelecimento aberto. Outro canal de comercialização tem sido as feiras livres, que são locais onde os produtores vendem diretamente seus produtos aos consumidores, os quais são geralmente informados quanto à procedência e qualidade destes.
Assim, a produção e o mercado de alimentos passaram a ter um papel dominante em relação aos canais alternativos de comercialização, sendo um desafio atual que visa a oferta de alimentos livres de agentes que podem pôr em risco a saúde do consumidor ${ }^{20}$. No Brasil, o indivíduo está continuamente avaliando as condições de consumo, sendo a escolha individual contextualizada a aspectos que influenciam o consumo final.

A qualidade sanitária das hortaliças consumidas pela população tem sido avaliada por alguns autores, e o risco de contaminação depende, entre outros fatores, da freqüência com que os cistos de protozoários e ovos de helmintos aparecem nesses alimentos ${ }^{21,22}$. Estudos realizados não só no Brasil ${ }^{22,23}$, mas também no México $^{24}$ e na Noruega ${ }^{25}$, mostraram elevados índices de contaminação parasitária em hortaliças. Guilherme et al. ${ }^{23}$ registraram nas hortaliças comercializadas na Feira do Produtor, em Maringá/ PR, $16,6 \%$ de enteroparasitas, e Silva et al. ${ }^{26}$ encontraram um índice de $21,4 \%$ em amostras coletadas da zona sul e norte da cidade do Rio de Janeiro. Neste trabalho, o percentual de contaminação parasitária encontrada foi superior, quando comparado a outros trabalhos ${ }^{16,17,21,23}$.

A contaminação de verduras consumidas cruas tem importante papel na disseminação dos enteroparasitas, sendo importante a averiguação das condições higiênicas que envolvem o sistema e água de irrigação, tipo de adubo utilizado, embalagem e transporte das hortaliças, caracterização da efetividade dos processos físicos e químicos de desinfecção, reconhecimento dos microorganismos ambientais e sua relação com gêneros alimentícios e contribuição para o processo de educação sanitária dos manipuladores e consumidores de alimentos $^{16,17}$.

A Tabela 1 mostra que as hortaliças mais contaminadas foram as provenientes dos pontos de comercialização em "sacolões". A relação entre cultivo e ver- 
duras contaminadas com parasitas intestinais tem sido ressaltada por muitos autores, que enfatizam a importância da água de irrigação $0^{4,27,28}$. Neste trabalho, algumas hipóteses foram levantadas para explicar o maior parasitismo desses produtos. É possível, por exemplo, que os fornecedores de hortaliças para os supermercados e feira livre utilizem para irrigação desses produtos águas de córregos naturais, enquanto os que fornecem hortaliças para "sacolões" usam águas do rio Rachadel, que é responsável também pelo abastecimento hídrico de Antônio Carlos (Tabela 2). Neste artigo, embora não se pretenda detalhar os problemas ambientais localizados, há indicações de lançamento de esgoto domiciliar neste rio, o que poderia contribuir para maior contaminação parasitária das referidas hortaliças.

Tanto o acondicionamento como o transporte podem influir na taxa de contaminação das hortaliças ${ }^{25,26}$. Nesta pesquisa, observou-se que as condições de cultivo e manipulação das hortaliças, durante a produção, coleta, transporte e armazenamento, fornecidas aos "sacolões" foram inferiores aos dos produtores dos supermercados. Notou-se ainda que os primeiros não usavam luvas durante a coleta, que nem todas as verduras eram embaladas em sacos plásticos e que o transporte destas, na sua maioria, era feito em caminhão aberto. Além disso, as propriedades rurais desses produtores não possuíam alvará da prefeitura.

A Tabela 2 mostra ainda que todos os agricultores utilizavam o estrume como adubo, sendo que um dos agricultores que forneciam hortaliças para o "sacolão" 1 utilizava esterco de boi. Embora a incidência real de doenças associadas a essa contaminação ainda não tenha sido avaliada, sabe-se que raramente o estrume é armazenado por tempo suficiente para prevenir a contaminação dos alimentos e da água por agentes patogênicos. Talvez este hábito possa explicar o alto de grau de parasitismo em todas as hortaliças analisadas, principalmente aquelas que foram obtidas do "sacolão" 1. É necessário, portanto, que os serviços de extensão rural orientem os agricultores para manejarem adequadamente o estrume, focalizando os cuidados domésticos no preparo e consumo dos alimentos.

$O$ resultado desta pesquisa mostra que o consumo de hortaliças na sua forma in natura pode expor a população a uma contaminação por agentes parasitários. Assim, é essencial conhecer a procedência do produto, com o propósito de controlar a ocorrência das doenças parasitárias provocadas pela ingestão de alimentos supostamente saudáveis. O alvará da prefeitura, o freqüente exame parasitológico dos manipuladores de alimentos e um sistema de produção adequado são ferramentas indispensáveis, nesse sentido.

Os dados deste trabalho enfatizam ainda a necessidade do cumprimento da legislação vigente e a detecção das condições de risco à Saúde Pública em relação ao fluxo de produção, manipulação e venda de hortaliças. Além disso, há também necessidade de atividades educativas permanentes dirigidas aos consumidores e manipuladores de alimentos, alertando para os riscos representados pela manipulação inadequada, pois nenhuma forma de controle alimentar é eficaz sem o apoio da maioria dos interessados e o respaldo da opinião pública bem informada. Os programas governamentais não podem deixar de considerar a segurança alimentar como componentes estratégicos de conscientização coletiva, traçando diretrizes básicas para os diversos campos de atuação e cenários, no sentido de valorizar a qualidade de vida da população. A soma de pequenos esforços, a mudança de comportamento e hábitos são os caminhos para se resolver os grandes problemas de Saúde Pública. 


\section{Referências}

1. Muniz RC, Queiroz MI. Relação entre desnutrição energético-protéica, vitamina A, e parasitoses em crianças vivendo em Brasília. Rev Soc Bras Med Trop 2002; 35: 133-42.

2. Ferreira P, Ribeiro M, Batista F. Ocorrência de parasitas e comensais intestinais em crianças de escola localizada em assentamento de sem-terras em Campo Florido, Minas Gerais, Brasil. Rev Soc Bras Med Trop 2003; 36(1): 109-11.

3. Branco JR, Rodrigues JC. Importância dos aspectos sanitários e educacionais na epidemiologia de enteroparasitoses em ambientes rurais. Rev Bras Anal Clin 1999; 31(2): 87-9.

4. Simões M, Pisani B, Marques EGL, Prandi MAG, Martini MH, Chiarini, PF. et al. Hygienic-sanitary conditions of vegetables and irrigation water from kitchen gardens in the municipality of Campinas, SP. Braz J Microb 2001; 32: 331-3.

5. Pupulim NRT, Guilherme ALF, Falavigna ALM. Uma tentativa de orientar comunidades escolares no controle de parasitoses. Rev Bras Anal Clin Paraná 1996; 28: 130-3.

6. Wanderley AAS, De Andrade GV, Silva EMA. A ocorrência de enteroparasitoses na população do município de Maxaranguape/RN. Rev NewsLab 2000; 42: 180-92.

7. Coulter JBS. Global importance of parasitic disease. Current Pediatrics 2002; 12(7): 523-33.

8. Marthrop-Clewes CA, Shaw C. Parasites. Britsh Med Bull 2000; 56: 193-8.

9. Costa-Cruz JM, Cardoso ML, Marques DE. Intestinal parasites in school food handlers in the city of Uberlândia, Minas Gerais, Brazil. Rev Inst Med Trop 1995; 37: 191-6.

10. Nolla AC, Cantos GA. Relação entre ocorrência de enteroparasitoses em manipuladores de alimentos e aspectos epidemiológicos em Florianópolis-SC. Cad Saúde Pública 2005; 21: 109-18.

11. De Rezende CH, Costa-cruz JM, Gennari-Cardoso ML. Enteroparasitoses em manipuladores de alimentos de escolas públicas em Uberaba (Minas Gerais), Brasil. Rev Panam Saúde Pública 1997; 2 (6): 392-7.

12. Cantos GA, Soares B, Maliska C, Glick D. Estruturas parasitárias encontradas em hortaliças comercializadas em Florianópolis, Santa Catarina. Rev NewsLab 2004; 66: 154-63.

13. Oliveira CAF, Germano PML. Estudo da ocorrência de enteroparasitas em hortaliças comercializadas na região metropolitana de São Paulo-SP, Brasil. I- Pesquisa de helmintos. Rev Saúde Pública 1992; 26(4): 283-9.

14. Levine DM, Berenson ML, Stephan D. Estatística: teoriae aplicações. Rio de Janeiro: LTC; 1998.
15. Bussab WO, Moretin PA. Estatística Básica. 5.ed. São Paulo: Saraiva; 2002.

16. Marzochi MCAA. Estudo dos fatores envolvidos na disseminação dos enteroparasitas. II- Estudo da contaminação de verduras e solo na cidade de Ribeirão Preto, São Paulo, Brasil. Rev Inst Med Trop 1997; 19: 14855.

17. Gelli DS, Tachibana T, Oliveira IR. Condições higiênicosanitárias de hortaliças comercializadas na cidade de São Paulo, SP, Brasil. Rev Inst Adolfo Lutz 1979; 39(1):37-43.

18. Blaser MJ. How safe is our food? New England J Med 1996 334: 1324-6.

19. Käferstein F, Abdussalam M. Food safety in the $21^{\text {st }}$ century. Bull World Health Organiz 1999; 77: 347-51.

20. Valente D, Passos ADC. Assessment of hygiene, sanitary, physical and structural aspects of supermarkets in a Southeastern city in Brazil. Rev Bras Epidemiol 2004; 7(1): 80-7.

21. Coelho LPS, Oliveira SM, Milman MHA. Detecção de formas transmissíveis de enteroparasitas na água e nas hortaliças consumidas em comunidades escolares de Sorocaba, São Paulo, Brasil. Rev Soc Bras Med Trop 2001; 34(5): 479-82.

22. Takayanagui OM, Oliveira CD, Bergamini AMM. Fiscalização de verduras comercializadas no município de Ribeirão Preto, SP. Rev Soc Bras Med Trop 2001; 34(1): 37-41.

23. Guilherme ALF, Araújo SM, Falavigna DLM, Pupulim AR, Dias ML, Oliveira HS. et al. Prevalência de enteroparasitas em horticultores e hortaliças da Feira de Maringá, Paraná. Rev Soc Bras Med Trop 1999; 32: 405-11.

24. Tsuji V, Barbarosa M, Zavala T. Vegetables for human consumption as probable source of Toxocara sp. Infection in man. Bol Chileno Parasitol 1997; 52(3): 47-50.

25. Robertson LJ, Gjerde B. Ocurrence of parasites on fruits and vegetables in Norway. J Food Protec 2001; 64: 1793-8.

26. Silva JP, Marzochi MCA, Camilo-Coura L. Estudo da contaminação por enteroparasitas em hortaliças comercializadas nos supermercados da cidade do Rio de Janeiro. Rev Soc Bras Med Trop 1995; 28: 237-41.

27. Hunter C, Perkins J, Tranter J. Agricultural land-use effects on the indicator bacterial quality of an upland stream in the Derbyshire peak distritic in the U.K. Water Res 1999; 33(17): 3577-86.

28. Gallegos E, Warren A, Robles E. The effects of Wastewater irrigation on groudwater quality in Mexico. Water Scien Techol 1999; 40(2): 45-52.

Recebido em: 09/06/05

Versão reformulada reapresentada em: 10/11/05 Aprovado em: 10/11/05 